\title{
Lidar measurements of mesospheric temperature inversion at a low latitude
}

\author{
V. Siva Kumar ${ }^{1}$, Y. Bhavani Kumar ${ }^{1}$, K. Raghunath ${ }^{1}$, P. B. Rao ${ }^{1}$, M. Krishnaiah ${ }^{2}$, K. Mizutani ${ }^{3}$, T. Aoki ${ }^{3}$, M. Yasui ${ }^{3}$, \\ and T. Itabe ${ }^{3}$ \\ ${ }^{1}$ National MST Radar Facility, P. B. No: 123, Tirupati - 517 502, A. P. India \\ ${ }^{2}$ Department of Physics, S. V. University, Tirupati - 517 502, A. P. India \\ ${ }^{3}$ Communication Research Laboratory, 4-2-1, Nukai Kitamachi, Koganei, Tokyo 184-8795, Japan
}

Received: 23 November 2000 - Revised: 7 May 2001 - Accepted: 29 May 2001

\begin{abstract}
The Rayleigh lidar data collected on 119 nights from March 1998 to February 2000 were used to study the statistical characteristics of the low latitude mesospheric temperature inversion observed over Gadanki $\left(13.5^{\circ} \mathrm{N}, 79.2^{\circ} \mathrm{E}\right)$, India. The occurrence frequency of the inversion showed semiannual variation with maxima in the equinoxes and minima in the summer and winter, which was quite different from that reported for the mid-latitudes. The peak of the inversion layer was found to be confined to the height range of 73 to $79 \mathrm{~km}$ with the maximum occurrence centered around $76 \mathrm{~km}$, with a weak seasonal dependence that fits well to an annual cycle with a maximum in June and a minimum in December. The magnitude of the temperature deviation associated with the inversion was found to be as high as $32 \mathrm{~K}$, with the most probable value occurring at about $20 \mathrm{~K}$. Its seasonal dependence seems to follow an annual cycle with a maximum in April and a minimum in October. The observed characteristics of the inversion layer are compared with that of the mid-latitudes and discussed in light of the current understanding of the source mechanisms.
\end{abstract}

Key words. Atmospheric composition and structure (pressure, density and temperature). Meterology and atmospheric dynamics (climatology)

\section{Introduction}

The mesospheric temperature inversion is an interesting feature which was first reported from a rocket experiment (Schmidlin, 1976) and more extensively since then by using Rayleigh lidar observations (Hauchecorne et al., 1987; Meriwether et al., 1994; Whiteway et al., 1995). The observations of Hauchecorne et al. (1987) from two stations in the south of France showed that the occurrence of the inversion has semiannual variation with maxima in summer and winter. The deviation associated with the inversion was found to be

Correspondence to: P. B. Rao (nmrf@isro.ernet.in) as high as $40 \mathrm{~K}$ and it occurs in the height range of $55-72 \mathrm{~km}$ in winter and $70-83 \mathrm{~km}$ in summer. The observed inversion was explained by the heating of the turbulent layers generated by the continuous breaking of the upward propagating internal gravity waves. In a subsequent study, however, employing a two-dimensional dynamical model of gravity wave breaking, it was shown that adiabatic heating associated with descending motions is the main mechanism involved in the formation of the mesospheric inversions (Hauchecorne and Maillard, 1990). This model, as it turned out, was unable to produce inversions in the summer hemisphere and at latitudes below $50^{\circ}$. Using the Rayleigh lidar observations made at Wright Patterson Air Force Base (Dayton, Ohio USA), Meriwether et al. (1994) reported temperature inversions with amplitudes ranging from $20 \mathrm{~K}$ to as much as $100 \mathrm{~K}$. The layer was located at $85 \mathrm{~km}$ during summer and at $70-75 \mathrm{~km}$ during winter. There was no indication of any inversion layer during either of the two equinoctial periods. The winter profiles showed evidence of long period waves passing through the inversion, while in summer, the wave activity was weak near the inversion layer. Further observations of mesospheric temperature inversions were reported using the Rayleigh lidar at York University, near Toronto (Whiteway et al., 1995). The inversion amplitude measured up to $30 \mathrm{~K}$ and its occurrence was found to be the highest (90\%) from November to February, and the lowest (20\%) from May to July. The occurrence height was below $70 \mathrm{~km}$ during winter and above that height during summer. The most interesting aspect of the observations was that the inversions were associated with an overlying, nearly adiabatic lapse rate, which was interpreted as an indication of a well-mixed turbulent layer. Following Chandra (1980), a one-dimensional numerical model was applied to demonstrate that a well-mixed turbulent layer can bring about a thermal structure quite similar to the one that was commonly observed. The other lidar observations that showed an anomalous feature in the mesospheric thermal structure include that from the $\mathrm{Na}$ lidar facilities located at Urbana, Illinois and Fort Collins, Colarado (Bills and Gard- 

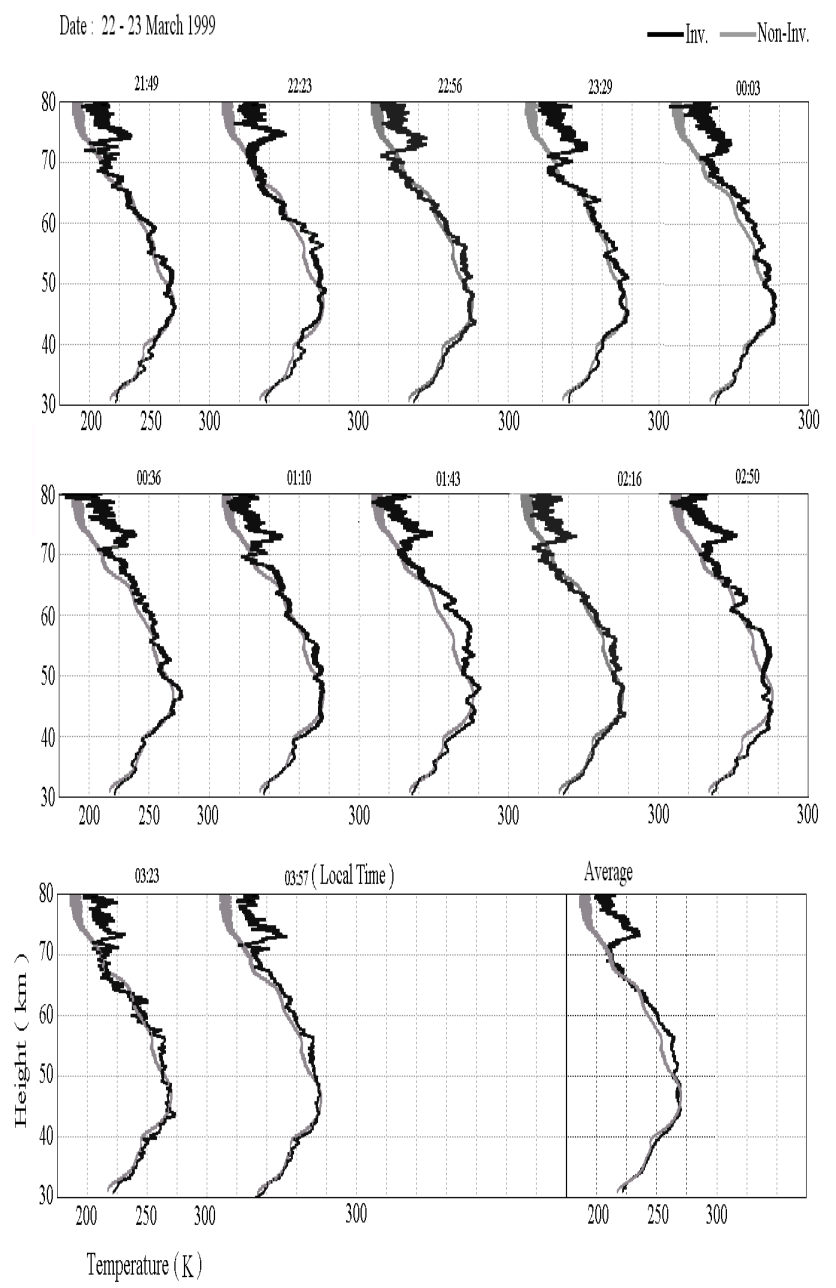

Fig. 1. A sequence of temperature profiles averaged over $33.3 \mathrm{~min}$ utes along with the whole night average profile observed on the inversion day of 22-23 March 1999. The gray colour plot presented for comparison represents the average profile for 3 non-inversion days in the month of March 1999.

ner, 1993; She et al., 1993). These observations revealed that the temperature inversion will often develop in conjunction with the propagation of a long period wave through the mesopause region.

In addition to the lidar observations, satellite measurements also provided evidence for the temperature inversion in the mesosphere. Using the Solar Mesosphere Explorer (SME) data for the period of 1982-1986, Clancy and Rusch (1989) and Clancy et al. (1994) observed inversions characterized by a semiannual cycle with maxima in the equinoctial low latitudes and an annual cycle with a maximum in the winter mid-latitudes. More recently, Leblanc and Hauchecorne (1997) presented a detailed climatology of the mesospheric temperature inversions using an extensive data set covering the years 1981-1993 from two lidars located in the south of France and observations from two satellite experiments, ISAMS (Improved Stratospheric And Meso- spheric Sounder) and HALOE (Halogen Occultation Experiment) on board the Upper Atmosphere Research Satellite (UARS). The observations showed the development of a mid-latitude belt of strong inversions $(\sim 40 \mathrm{~K})$ in the height range of 70-75 km during winter and a lower latitude belt of strong inversions over $80-85 \mathrm{~km}$ occurring a few weeks after the equinoxes. These measurements, in agreement with those reported earlier, clearly revealed the important features of the inversions: the semiannual cycle observed near the equator and the annual cycle at mid-latitudes.

In order to interpret the observed temperature inversions in the mesosphere, several source mechanisms have been proposed and they have recently been reviewed in some detail by Meriwether and Gardner (2000). The mechanisms include primarily gravity wave breaking, gravity wave-tidal interactions and chemical heating. The gravity wave breaking, through wave dissipation, has been estimated to provide a heating rate of about $10 \mathrm{~K} / \mathrm{d}$ (e.g. Fritts and van Zandt, 1993). From in situ rocket measurements at high latitudes, however, Lübken (1997) showed that the turbulent heating rates are fairly small $(\sim 1-2 \mathrm{~K} / \mathrm{d})$ for winter, although significantly high $(\sim 10-20 \mathrm{~K} / \mathrm{d})$ around the summer mesopause $(\sim 90 \mathrm{~km})$. The role of semi-diurnal and diurnal tides in causing the inversions has been studied by Meriwether et al. (1998) by comparing the observed mesosphere thermal structure with that predicted by a Global Scale Wave Model (GSWM) for a mid-latitude. In finding the observed amplitudes of heating and cooling to be about 10 times larger than the predicted GSWM values, they suggested that the inversions are possibly caused through an amplification mechanism based upon the interactions of the gravity waves with the tidal structure (Liu and Hagen, 1998). While the dynamics associated with gravity wave breaking are considered an important source, Meriwether and Mlynczak (1995) drew attention to the possibility of an additional source involving exothermic chemical reactions contributing significantly to the formation of an inversion layer in the mesosphere. Since the reaction involving ozone and atomic hydrogen provides the most dominant contribution, it may be expected that chemical heating would be most effective in the summer when the ozone levels are high and least effective in the winter when they are low. Using a two-dimensional model, and combining mesosphere photochemistry with the dynamical transport of long-lived species, it was shown that the region of $80-95 \mathrm{~km}$ may be heated by as much as 3 to $10 \mathrm{~K} / \mathrm{d}$, which is of the same order as that due to the dissipation of gravity waves, as calculated by Fritts and vanZandt (1993).

The present study is based on 119 nights of Rayleigh lidar observations of the middle atmospheric thermal structure carried out at Gadanki $\left(13.5^{\circ} \mathrm{N}, 79.2^{\circ} \mathrm{E}\right)$, India from March 1998 to February 2000. The mesospheric temperature inversions were noted as a common feature and their statistical characteristics are presented for the first time for a low latitude. The observed characteristics are compared with that of the mid-latitudes and discussed in terms of the possible source mechanisms. 


\section{System description and data analysis}

A state-of-the-art Rayleigh-Mie lidar system was installed in March 1998 at Gadanki $\left(13.5^{\circ} \mathrm{N}, 79.2^{\circ} \mathrm{E}\right)$, India under an Indo-Japanese collaboration program. The lidar system consists of a laser pulse transmitter, two receiving telescopes and data acquisition and processing subsystems. The lidar transmitter employs the second harmonic of Nd-YAG pulsed laser at $532 \mathrm{~nm}$ with a pulse energy of about $550 \mathrm{~mJ}$. The lidar operates at a pulse repetition frequency of $20 \mathrm{~Hz}$ and a pulse width of $7 \mathrm{~ns}$. The transmit beam, with a divergence of $0.1 \mathrm{mrad}$, is directed vertically by a flat mirror oriented at $45^{\circ}$ to the beam axis. There are two receiver subsystems, one to measure temperature using Rayleigh backscatter and the other to determine aerosol concentration using the Mie component of the backscatter. The Rayleigh receiver employs a Newtonian telescope with a primary mirror having an effective diameter of $75 \mathrm{~cm}$. A narrow band interference filter with a full-width at a half-maximum (FWHM) of $1.07 \mathrm{~nm}$ is used to reject much of the background light. The signal is then split into two channels in the ratio of 9:1, the high gain channel, $R$, to cover $50-80 \mathrm{~km}$, where the signal is weak, and the low gain channel, $U$, to cover $30-50 \mathrm{~km}$, where the signal is relatively stronger. The signals are directed to photomultiplier tubes (PMTs), which operate in photon count mode for both channels. The outputs of the PMTs are given to pulse discriminators consisting of a $300 \mathrm{MHz}$ pulse amplifier with a threshold adjustable comparator and a shaper circuit. The outputs of the two discriminators of the $R$ and $U$ channels are connected to a PC-based photon counting data acquisition system, employing a multi-channel scalar plug-in card (MCS-Plus). The MCS-Plus works with dwell times ranging from $2 \mu$ s to $1800 \mathrm{~s}$ and a maximum memory length of 8192 channels with input counting rates up to $100 \mathrm{MHz}$. Using a $2 \mu \mathrm{s}$ dwell time and a 5000 laser-shot average, the photon count profiles are recorded with a time resolution of $250 \mathrm{~s}$ and a range resolution of $300 \mathrm{~m}$. The photon count profiles thus obtained form the basic database from which the temperature profiles are derived. Due to the high background sunlight during the daytime, the temperature measurements by lidar are limited to nighttime.

The method of analysis adopted for the determination of the temperature profile from the Rayleigh backscatter data of the photon count profiles follows closely that given by Hauchecorne and Chanin (1980). In the height range $(>30 \mathrm{~km})$, where the Mie backscatter contribution is negligible, the recorded signal intensity, corrected for the range and atmospheric transmission, is proportional to the molecular number density. Using the number density taken from an appropriate atmospheric model (COSPAR International Reference Atmosphere, CIRA-86) for the height of $50 \mathrm{~km}$, where the signal-to-noise ratio is fairly high, the normalisation constant is evaluated and thereby, the density profile is derived. By taking the pressure at the top of the height range $(90 \mathrm{~km})$ from the atmospheric model, the pressure profile is computed using the measured density profile, assuming the atmosphere is in hydrostatic equilibrium. By adopting the perfect gas
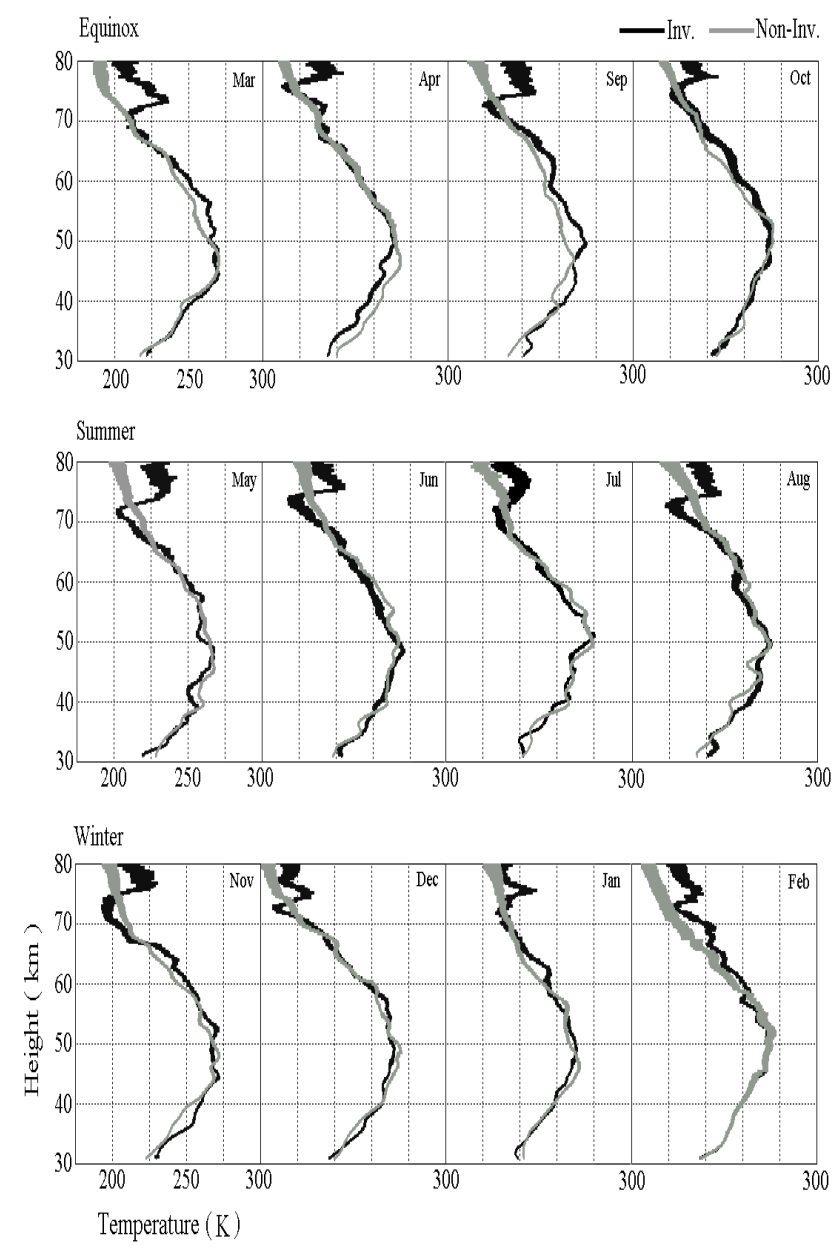

Fig. 2. Typical inversion day average temperature profiles, one for each month, along with the monthly average profile for the noninversion days (gray colour plot).

law, the temperature profile is computed using the derived density and pressure profiles. Any uncertainty in the pressure at the top of the profile would contribute to temperature uncertainty that falls rapidly with decreasing altitude. For a $10 \%$ change in the pressure at the top $(90 \mathrm{~km})$, the temperature changes by less than $1 \mathrm{~K}$ at $75 \mathrm{~km}$. The basic temperature profile thus derived has a time resolution of $250 \mathrm{~s}$ and a range resolution of $300 \mathrm{~m}$. The temperature inversion of interest here is considered statistically significant if the amplitude of the inversion exceeds twice the standard deviation for the case when the profiles are integrated for $33.3 \mathrm{~min}$ utes, which corresponds to an average of 40000 laser pulses. Adopting this criterion, a temperature inversion is counted as such if its amplitude exceeds a threshold of $12 \mathrm{~K}$.

\section{Observations and discussion}

The Rayleigh lidar observations of temperature profiles for the height range of 30-80 km were made on 119 clear nights with a distribution of 44 during equinoxes (March, April and 
September, October), 30 in summer (May, June, July and August) and 45 in winter (November, December, January and February) from March 1998 to February 2000. The data were collected for four to six hours continuously, with a time resolution of $250 \mathrm{~s}$ during the interval of 2100-0400 LT. Figure 1 shows for an inversion night (22-23 March 1999), a sequence of profiles, each representing an average of eight profiles (33.3 minutes), along with the average profile for the whole night. The gray colour plot shown for comparison is the average profile for 3 non-inversion days in March 1999. The thickness of the curves represents twice the standard deviation. The inversion persists throughout the night without much variability. The inversion peak occurs around $73 \mathrm{~km}$ and has an average magnitude of about $30 \mathrm{~K}$ with reference to the average non-inversion profile. Figure 2 shows sample inversion profiles for one night in each month, along with the monthly average non-inversion profile for the three seasons: equinox, summer and winter. The inversion is found to be confined to the height range of $70-80 \mathrm{~km}$, with its maximum amplitude exceeding $30 \mathrm{~K}$. It is significant that the inversion occurs with an accompanied cooling in the lower part as, for example, in May, and also without cooling, as in March. The lapse rates above and below the inversion layer are found to be mostly less than the adiabatic lapse rate. Presented in Figs. $3 a-c$ are the statistical distributions characterizing the height of occurrence, temperature deviation and monthly occurrence of the inversion. The peak of the inversion layer is confined to the height range of 73 to $79 \mathrm{~km}$, with the maximum occurrence around $76 \mathrm{~km}$. The magnitude of the temperature deviation associated with the inversion is characterized by a broad distribution with a maximum as high as $32 \mathrm{~K}$, with the most probable value occurring over 18 to $20 \mathrm{~K}$. The lower limit of $12 \mathrm{~K}$ is set by the criterion that for an inversion to be considered significant, it had to exceed twice the standard deviation. The monthly variation of the frequency of occurrence shows that it has the highest value in March (78\%), with a secondary peak in October $(56 \%)$. The minima occurring in the summer and winter months are around $40 \%$. To understand the nature of the variation better, a least squares fit of the semiannual oscillation (SAO) and the annual oscillation (AO) has been made to the observed data, as shown in Fig. 3c. The SAO fit is found to be slightly better with an RMS deviation of 8.5 relative to that of $\mathrm{AO}$ with an RMS deviation of 10.3. The lidar and satellite observations reported by Leblanc and Hauchecorne (1997) showed that the frequency of occurrence follows an annual cycle with a maximum during the winter months at mid-latitudes and a semiannual cycle with maxima during the equinoxes at low latitudes. Thus, although in agreement with the satellite measurements, the semiannual variation seen in the present observations needs to be confirmed further based on a larger database. The monthly variations of occurrence height and temperature deviation are shown in Figs. $4 a$ and b, respectively. In both cases, the data are found to fit much better to the annual oscillation (AO) compared to the semiannual oscillation (SAO), and so the least squares fits of $\mathrm{AO}$ are shown in the plots (open circles in Figs. $4 a$ and b). The

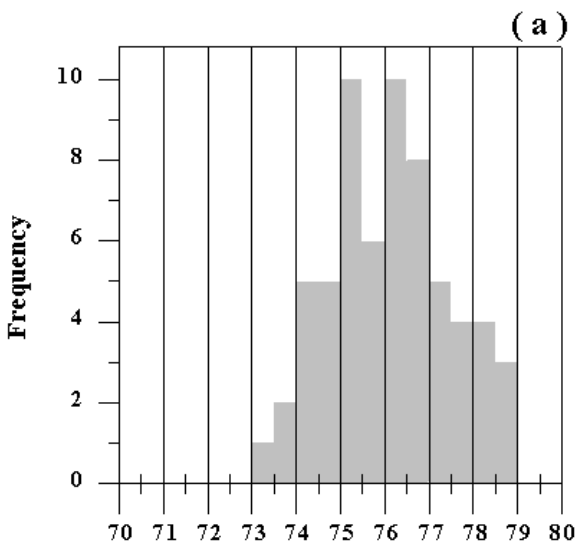

Height of Occurrence ( $\mathrm{km}$ )
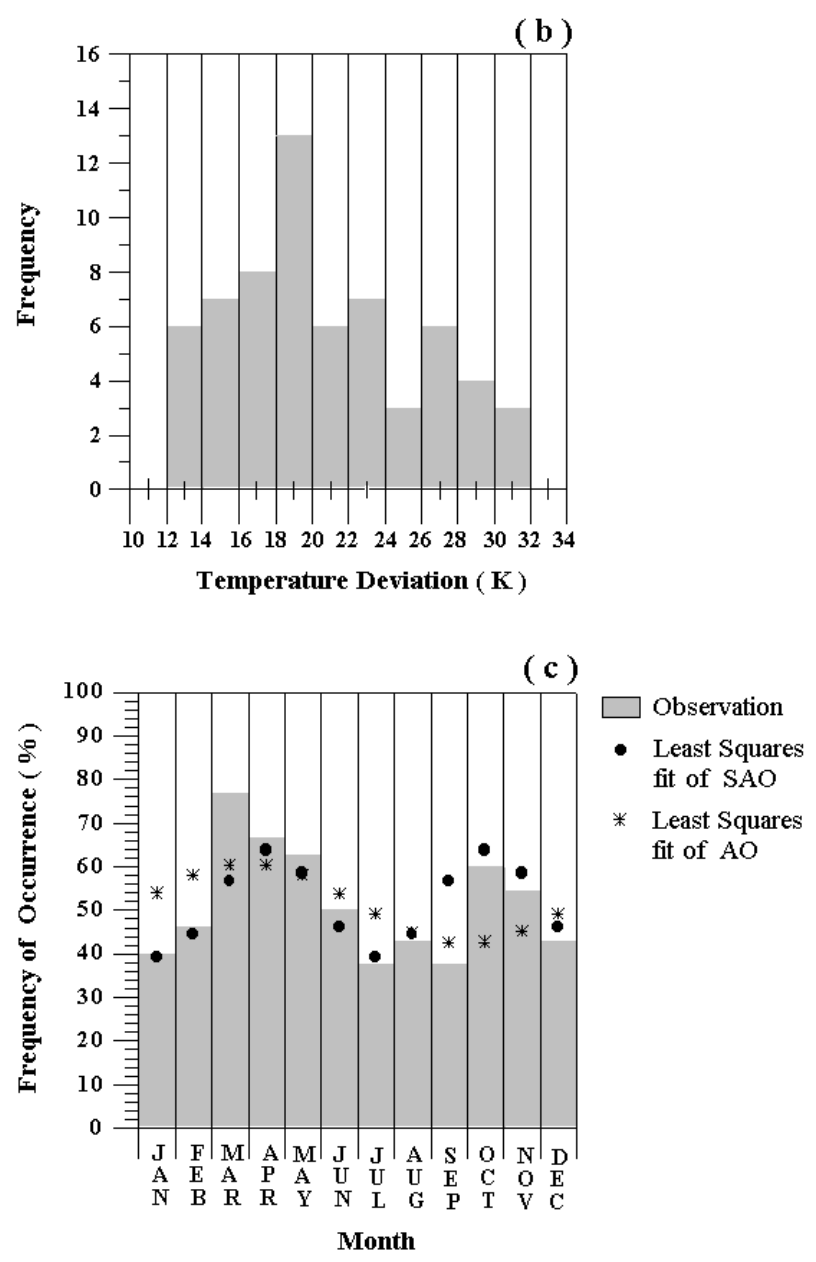

Fig. 3. Mesospheric temperature inversion frequency distributions for (a) height of occurrence, (b) temperature deviation, and (c) monthly percentage occurrence.

height variation of the inversion peak over the year is found to be fairly small, with the maximum height of $78 \mathrm{~km}$ and the minimum of $74 \mathrm{~km}$ occurring in July and December, respectively. The least squares fit has an RMS deviation of about 
$0.5 \mathrm{~km}$. The maximum and minimum temperature deviations occur in May and December with values of $31 \mathrm{~K}$ and $14 \mathrm{~K}$, respectively. The RMS deviation of the least squares fit is found to be about $2.8 \mathrm{~K}$.

From a comparison of the above low latitude observations with that reported for the mid-latitudes, the following important points emerge:

- Once they have occurred, low latitude inversions also last throughout the night, as they do at mid-latitudes.

- The low latitude inversions are somewhat weaker, but closely resemble those reported for a mid-latitude by Hauchecorne et al. (1987).

- While the mid-latitude observations revealed lapse rates close to adiabatic for several kilometers above the inversion (Whiteway et al., 1995), the present observations do not indicate such a trend, although it is rather difficult to say conclusively due to the limited height coverage above the inversion.

- The seasonal dependence of the inversion is found to be remarkably different for low and mid-latitudes. It occurs most preferably in winter, with the frequency of occurrence following an annual cycle at mid-latitudes. From the present observations for a low latitude, however, we found that the occurrence frequency has the maximum in the spring equinox and its variation seems to follow a semiannual cycle. This latitude dependence of the seasonal behaviour is found to be in agreement with that reported by Leblanc and Hauchecorne (1997).

- The seasonal variations of the inversion height and temperature deviation observed for the low latitude are found to follow an annual cycle, as was the case for midlatitudes. The magnitude of height variation, however, was found to be rather small for the low latitude, as seen from the present observations.

The observed mesospheric inversions have largely been interpreted in terms of the mechanisms involving gravity wave breaking, gravity wave-tidal interactions and chemical heating. An important factor linking the gravity wave activity to the inversion layer is the difference in the seasonal dependence of the inversion layer between low and mid-latitudes. From a comprehensive study of gravity wave activity in the middle atmosphere, it was shown that the wave activity is at a maximum in winter at high latitudes, and in equinoxes at low latitudes (Hirota, 1984; Fritts, 1984). This seasonal and latitudinal behavior of the gravity wave activity is in precise agreement with that of the inversion layer. Leblanc and Hauchecorne (1997) explained in detail the mechanism by which the gravity wave breaking would induce a meridional cell that was able to produce temperature inversions with amplitudes of $15 \mathrm{~K}$ in the higher winter latitudes. They pointed out, however, that this mechanism would not operate effectively to account for the equinoctial low latitude inversions. Using a model based on Chandra (1980), White-
I Observation

$\circ$ Least Squares fits of $\mathrm{AO}$
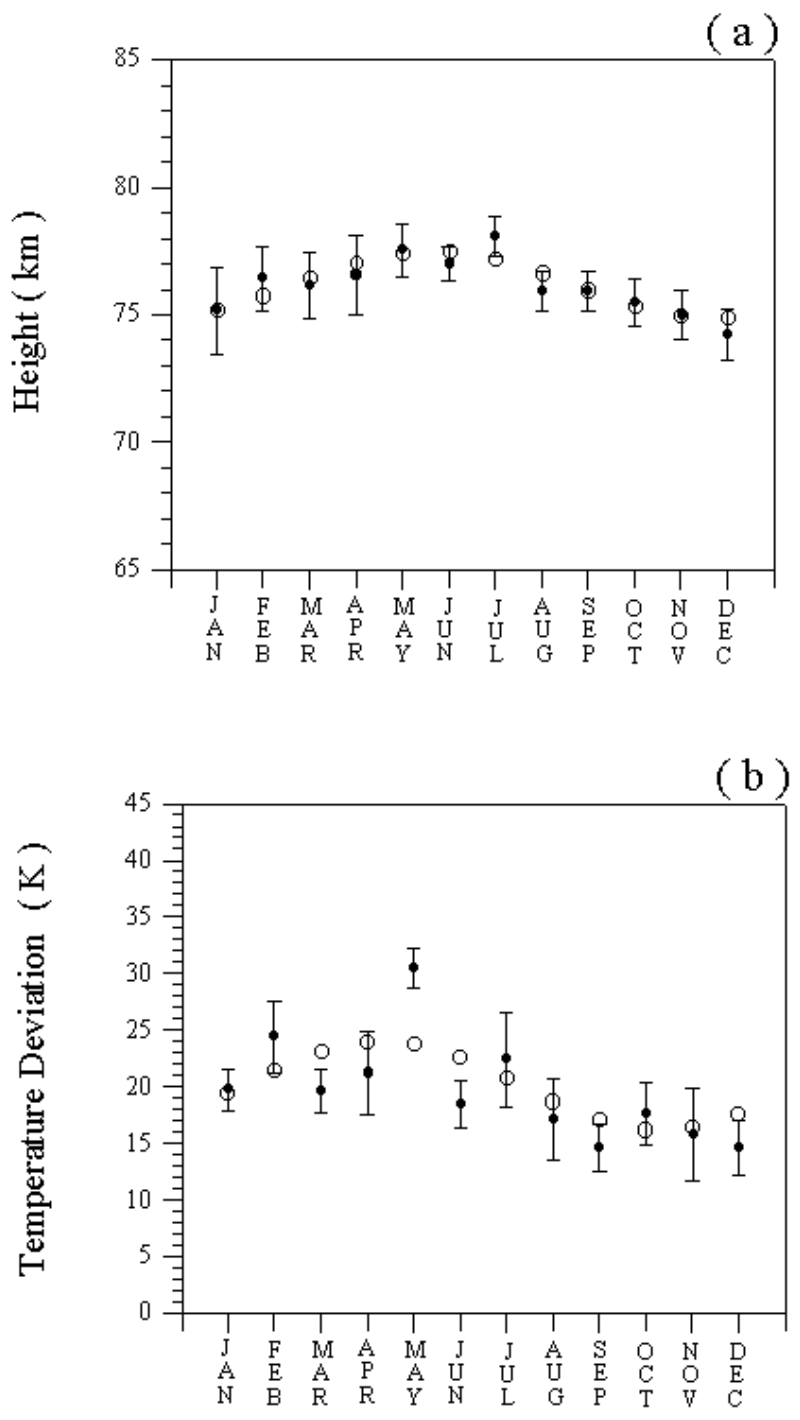

Month

Fig. 4. Monthly variations of (a) peak height and (b) magnitude of the mesospheric temperature inversion.

way et al. (1995) estimated the heating rates due to turbulent diffusion with dissipation as high as $15-20 \mathrm{~K}$. These estimates, however, are based on an eddy diffusion coefficient of $300 \mathrm{~m}^{2} \mathrm{~s}^{-1}$, which is 3 times larger than that inferred from the in situ rocket measurements of density fluctuations carried out at high latitudes by Lübken (1997). The heating rates obtained by Lübken are $\sim 13 \mathrm{~K} / \mathrm{d}$ around $90 \mathrm{~km}$ in summer and $1-2 \mathrm{~K} / \mathrm{d}$ at $80-100 \mathrm{~km}$ in winter. Recently, Meriwether et al. (1998) suggested that the mesospheric inversions observed by the Rayleigh lidar during February 1995 at Logan, Utah are caused by a localized mechanism involving the coupling of gravity waves to the mesopause tidal structure. 
Liu and Hagen (1998) have demonstrated through a simulation the effect of gravity wave-tidal interaction on the mesosphere - lower thermosphere thermal structure. The simulation shows two inversion layers with a downward phase progression in the height ranges of $70-80 \mathrm{~km}$ and $100-110 \mathrm{~km}$. The present observations would indicate only the development of the lower inversion layer, with the height coverage limited to $80 \mathrm{~km}$. The simulation revealed that the lower level inversion could develop to an amplitude of about $10 \mathrm{~K}$. From the above discussion, it is not obvious that the dynamics associated with the gravity waves alone would be able to account for the observed inversions. Some recent observations made at Gadanki on consecutive days showed that an inversion could develop to a magnitude of $20 \mathrm{~K}$ from a condition of non-inversion on the previous day. To account for this rate of heating, it may be necessary to supplement the source associated with gravity wave breaking/interactions with an additional source which could be the chemical heating, as proposed by Meriwether and Mlynczak (1995).

Acknowledgement. The National MST Radar facility is operated by the Department of Space with partial support from the Council of Scientific and Industrial Research, Government of India. The authors would like to acknowledge with thanks the numerous contributions by their colleagues at the National MST Radar Facility (DOS), India and the Communications Research Laboratory (MOPT), Japan in establishing and operating the Lidar facility under an Indo-Japanese collaboration program.

Topical editor D. Murtagh thanks A. Hauchecorne and M. Alpers for their help in evaluating this paper.

\section{References}

Bills, R. E. and Gardner, C. S., Lidar observations of the mesopause region temperature structure at Urbana, J. Geophys. Res., 98, 1011-1021, 1993.

Chandra, S., Energetics and thermal structure of the middle atmosphere, Planet. Space Sci., 28, 585-593, 1980.

Clancy, R. T. and . Rusch, D. W., Climatology and trends of mesospheric $(58-90 \mathrm{~km})$ temperature based upon 1982-1986 SME limb scattering profiles, J. Geophys. Res., 94, 3377-3393, 1989.

Clancy, R. T., Rusch, D. W., and Callan, M. T., Temperature minima in the average thermal structure of the middle atmosphere (70$80 \mathrm{~km}$ ) from analysis of 40- to 92-km SME global temperature profiles, J. Geophys. Res., 99, 19001-19020, 1994.

Fritts, D. C., Gravity wave saturation in the middle atmosphere: A review of theory and observations, Rev. Geophys. Space Phys.,
22, 275-308, 1984.

Fritts, D.C. and vanZandt, T. E., Spectral estimates of gravity wave energy and momentum fluxes, 1. Energy dissipation, acceleration, and constraints, J. Atmos. Sci., 50, 3685-3694, 1993.

Hauchecorne, A. and Chanin, M. L., Density and temperature profiles obtained by lidar between 35 and $70 \mathrm{~km}$, Geophys. Res. Lett., 7, 565-568, 1980.

Hauchecorne, A. and Maillard, D., A 2-D dynamical model of mesospheric inversion in winter, Geophys. Res. Lett., 17, 21972200, 1990.

Hauchecorne, A., Chanin, M. L., and Wilson, R., Mesospheric temperature inversion and gravity wave breaking, Geophys. Res. Lett., 14, 933-936, 1987.

Hirota., I, Climatology of gravity waves in the middle atmosphere, in Dynamics of the Middle Atmosphere, edited by Holton, J. R. and Matsuno, T., p. 65, Terra, Tokyo, 1984.

Leblanc, T. and Hauchecorne, A., Recent observations of mesospheric temperature inversions, J. Geophys. Res., 102, 19471$19482,1997$.

Liu, H. L. and Hagan, M. E., Local heating/cooling of the mesosphere due to gravity wave and tidal coupling, Geophys. Res. Lett., 25, 941-944, 1998.

Lübken, F.-J., Seasonal variation of turbulent energy dissipation rates at high latitudes as determined by in situ measurements of neutral density fluctuations, J. Geophys. Res., 102, $13441-$ $13456,1997$.

Meriwether, J. W., Dao, P. D., McNutt, R. T., Klemetti, W., Moskowitz, W., and Davidson, G., Rayleigh lidar observations of mesosphere temperature structure, J. Geophys. Res., 99, $16973-$ 16987, 1994.

Meriwether, J. W. and Mlynczak, M. G., Is chemical heating a major cause of the mesosphere inversion layer?, J. Geophys. Res., 100, 1379-1387, 1995.

Meriwether, J. W., Gao, X., Wickwar, V., Wilkerson, T., Beissner, K., Collins, S., and Hagan, M., Observed coupling of the mesospheric inversion layer to the thermal structure, Geophys. Res. Lett., 25, 1479-1482, 1998.

Meriwether, J. W. and Gardner, C. S., A review of the mesospheric inversion layer phenomenon, J. Geophys. Res., 105, 12 40512416, 2000.

Schmidlin, F. J., Temperature inversion near 75 km, Geophys. Res. Lett., 3, 173-176, 1976.

She, C. Y., Yu, J. R., and Chen, H., Observed thermal structure of a mid-latitude mesopause, Geophys. Res. Lett., 20, 567-570, 1993.

Whiteway, J. A., Carswell, A. I., and Word, W. E., Mesospheric temperature inversions with overlaying nearly adiabatic lapse rate : An indication of a well-mixed turbulent layer, Geophys. Res. Lett., 22, 1201-1204, 1995. 